\title{
Entrance of the Tat protein of HIV-1 into human uterine cervical carcinoma cells causes upregulation of HPV-E6 expression and a decrease in p53 protein levels
}

\author{
GIOVANNI BARILLARI ${ }^{1}$, CLELIA PALLADINO ${ }^{2}$, ILARIA BACIGALUPO ${ }^{2}$, \\ PATRIZIA LEONE ${ }^{2}$, MARIO FALCHI $^{2}$ and BARBARA ENSOLI ${ }^{2}$ \\ ${ }^{1}$ Department of Clinical Sciences and Translational Medicine, University 'Tor Vergata', I-00133 Rome; \\ ${ }^{2}$ National AIDS Center, National Institute of Health, I-00161 Rome, Italy
}

Received December 18, 2015; Accepted June 16, 2016

DOI: $10.3892 /$ ol.2016.4921

\begin{abstract}
The infection of uterine cervical epithelial cells by oncogenic, high-risk human papilloma viruses (HR-HPVs) may lead to the development of cervical carcinoma. Of note, the incidence of this tumor is significantly increased in women infected by both HR-HPV and human immunodeficiency virus (HIV)-1. In this regard, previous studies have linked the HIV-1 Tat protein, a trans-activator of viral gene expression, to the pathogenesis of HIV-associated malignancies. In particular, it has been shown that upon its release by acutely infected cells, Tat protein can enter human cells, thus modifying their phenotype. Based on these findings, the present study evaluated whether extracellular Tat protein could be taken up by human uterine cervical carcinoma cells, and whether this could affect the expression of HPV (E6 or E7) or cellular (p16 or p53) molecules, which are key to cervical carcinoma development or progression. The results indicated that extracellular, biologically active HIV-1 Tat protein is taken up by human uterine cervical carcinoma cells, and that this is followed by an increase in the expression of the E6 protein of HPV, and by a reduction in the protein levels of the cellular oncosuppressor p53. Since p53 loss is associated with cell dedifferentiation and immortalization, these findings suggest a possible link between extracellular Tat protein and the high incidence and clinical aggressiveness of uterine cervical carcinoma observed in HIV/HPV doubly infected women.
\end{abstract}

Correspondence to: Professor Giovanni Barillari, Department of Clinical Sciences and Translational Medicine, University 'Tor Vergata', 1 Via Montpellier, I-00133 Rome, Italy

E-mail: barillar@uniroma2.it

Key words: uterine cervical carcinoma, HIV-1 Tat protein, human papilloma virus, E6, p53, p16

\section{Introduction}

Uterine cervical carcinoma is very frequent and aggressive in human immunodeficiency virus (HIV)/human papilloma virus (HPV) doubly infected women, compared with the general population (1). Although this is considered to depend on HIV-promoted immune deficiency favouring high-risk (HR)-HPV persistence in infected women (1), a direct pathogenic link may exist between HIV and uterine cervical carcinoma. In particular, it was previously shown that transfection of HR-HPV ${ }^{+}$human epithelial cells with HIV-1 Tat DNA is followed by an increase in the expression of HPV genes, including that encoding for the oncoprotein E6 (2). In this context, other studies indicated that degradation of the cellular oncosuppressor protein p53 by HPV-E6 prevents the differentiation, senescence and apoptosis of HPV-infected cells of the cervical epithelium basal layer (3).

Transfection of HIV DNA mimics HIV infection; however, one should consider that among the cell types present in the uterine cervix, only lymphocytes and macrophages permit HIV-1 productive infection (4), and consequently, the efficient expression of HIV-1 genes such as Tat.

Notably, previous studies have highlighted that i) HIV-infected lymphocytes release the HIV-1 Tat protein in a biologically active form that is able to enter neighboring, HIV-infected or uninfected cells (5); ii) extracellular Tat protein plays a key role in the pathogenesis of HIV-associated malignancies, including Kaposi's sarcoma and non-Hodgkin lymphoma (5); and iii) HIV-infected leukocytes infiltrate the uterine cervix (6).

Based on these findings, one could hypothesise that upon its release by HIV-infected leukocytes infiltrating the uterine cervix, biologically active HIV-1 Tat protein is taken up by $\mathrm{HR}_{-} \mathrm{HPV}^{+}$cervical epithelial cells, and that this could accelerate the progression of uterine cervical carcinoma.

Thus, the aim of the present study was to evaluate whether extracellular HIV-1 Tat protein enters human uterine cervical carcinoma cells, and whether this is followed by an alteration of HPV-E6 or p53 expression in these cells. In addition, the effect of Tat on the HPV-E7 oncogene and the HPV-linked p16 inhibitor of cyclin-dependent kinase 4a (ink4a) cell cycle inhibitor (7) was also evaluated. 


\section{Materials and methods}

Reagents. Recombinant Tat protein from HIV-1 (subtype B) was expressed, purified, handled and tested for biological activity as described earlier (8). The human cervical cancer cell line SiHa harbouring HR-HPV16 DNA was cultured according to the supplier's protocol (American Type Culture Collection, Manassas, VA, USA). Growth medium (Dulbecco's modified Eagle's medium), supplements, phosphate-buffered saline (PBS) solution and the monoclonal antibody directed against the E7 protein of HPV16 were obtained from Invitrogen (Thermo Fisher Scientific, Inc., Waltham, MA, USA). Monoclonal antibodies raised against the E6 protein of HPV16, human p53 (clone DO-1) and human p16 $6^{\text {ink4a }}$ were acquired from Santa Cruz Biotechnology, Inc. (Dallas, TX, USA). Anti- $\beta$-actin monoclonal antibodies, human plasma fibronectin (FN), bovine serum albumin (BSA, fraction V), doxorubicin hydrochloride and the chemicals employed for protein extraction were purchased from Sigma-Aldrich (St. Louis, MO, USA). The primers and probes employed for RNA analyses were purchased from Applied Biosystems (Thermo Fisher Scientific, Inc.).

Cell adhesion, growth and viability assays. For the adhesion assays, 96-well, flat-bottom, non-tissue culture-treated polystyrene plates (Invitrogen; Thermo Fisher Scientific, Inc.) were coated overnight at $4^{\circ} \mathrm{C}$ with Tat, FN or BSA. Plates were then rinsed and incubated for $3 \mathrm{~h}$ at room temperature with PBS-1\% BSA. A total of $100 \mu \mathrm{l}$ of the cell suspension $\left(5 \times 10^{5}\right.$ cells $/ \mathrm{ml}$ in serum-free medium) was added to the wells (in quadruplicate). Plates were incubated for $1 \mathrm{~h}$ at $37^{\circ} \mathrm{C}$ in a $5 \% \mathrm{CO}_{2}$ atmosphere and washed with PBS. The adherent cells were then fixed with $4 \%$ paraformaldehyde and stained with $1 \%$ toluidine blue (Sigma-Aldrich). Cell adherence was quantitated using a microtiter plate reader (Victor 1420; PerkinElmer, Inc., Waltham, MA, USA) set at $570 \mathrm{nM}$.

Cell growth or viability assays were performed by the cell counting method (9) or the trypan blue cell exclusion test (10), respectively.

Fluorescence microscopy. SiHa cells were plated on chamber slides (Thermo Fisher Scientific, Inc.), starved in serum-free medium, and then cultured in complete medium containing Tat or its suspension buffer (PBS-0.1\% BSA). After 30, 60 or $120 \mathrm{~min}$ of Tat addition to the growth medium, the cells were fixed in $2 \%$ paraformaldehyde, treated with permeabilizing solution (BD Biosciences, Franklin Lakes, NJ, USA), incubated first with rabbit polyclonal affinity-purified anti-Tat antibodies (dilution, 1:100; catalog no., ANT0041; Diatheva s.r.l., Fano, Italy) or rabbit immunoglobulin (Ig)G control antibodies (dilution, 1:100; catalog no., I-5006; Sigma-Aldrich), then with anti-rabbit fluorescein isothiocyanate-labeled antibodies (dilution, 1:100; catalog no., F-1262; Sigma-Aldrich) and finally stained with 4',6-diamidino-2-phenylindole (Sigma-Aldrich). Tat uptake and intracellular distribution were observed and photographed using fluorescence microscopy.

Intracellular Tat staining and flow cytometry. SiHa cells were suspended by trypsinization, incubated for $30 \mathrm{~min}$ at $37^{\circ} \mathrm{C}$ in complete medium containing Tat or its buffer, washed with cold medium, treated for 5 min with trypsin-ethylenediaminetetraacetic acid solution (Invitrogen; Thermo Fisher Scientific, Inc.) to remove cell surface-bound Tat, fixed for $10 \mathrm{~min}$ at $4^{\circ} \mathrm{C}$ with BD FACS ${ }^{\mathrm{TM}}$ lysing solution (BD Biosciences), exposed for $30 \mathrm{~min}$ at $4^{\circ} \mathrm{C}$ to permeabilizing solution (BD Biosciences), stained with rabbit polyclonal affinity-purified anti-Tat antibodies or rabbit IgG control antibodies, and analyzed by flow cytometry (8).

Polymerase chain reaction (PCR). Total RNA was extracted from the cells, purified and used to synthesise complementary (c)DNA as previously described (9). The reverse-transcribed (RT) cDNA from repeated, independent experiments was used for quantitative (q)PCR analysis of HPV-E6 or HPV-E7, according the TaqMan ${ }^{\mathrm{TM}}$ technique (Thermo Fisher Scientific, Inc.).

The primers for HPV16-E6 were: Forward, 5'-AATGTT TCAGGACCCACAGG-3' and reverse, 5'-TTGTTTGCAGCT CTGTGCAT-3'. The probe for HPV16-E6 was 5'-AGCGAC CCAGAAAGTTACCA-3'. The primers for HPV16-E7 were: Forward, 5'-CAAGTGTGACTCTACGCTTCGG-3' and reverse, 5'-GTGGCCCATTAACAGGTCTTCCAA-3'. The probe for HPV16-E7 was 5'-TGCGTACAAAGCACACAC GTAGACATTCGT-3'.

The RT reaction was normalized by amplifying samples for $\beta$-actin. The primers for $\beta$-actin were: Forward, 5'-AAG AGCTACGAGCTGCCTGA-3' and reverse, 5'-TGGAGTTGA AGGTAG TTTCGTG-3'. The probe for $\beta$-actin was 5'-CAT CACCATTGGCAATGAGCGGT-3'.

Amplification consisted of $20 \mathrm{sec}$ at $50^{\circ} \mathrm{C}, 10 \mathrm{~min}$ at $95^{\circ} \mathrm{C}$, $15 \mathrm{sec}$ at $95^{\circ} \mathrm{C}$ and $1 \mathrm{~min}$ at $58^{\circ} \mathrm{C}$ for 45 cycles. The complexes formed by PCR products and related probes were quantified by the $2-\Delta \Delta$ Cq method (11).

In other experiments, cDNA was amplified using the SYBR $^{\mathrm{TM}}$ Green technique (Thermo Fisher Scientific, Inc.), and the following oligonucleotide primers derived from the $\mathrm{p} 53$ cDNA sequence: Forward, 5'-TCTGACTGTACCACCATC CACTA-3' and reverse, 5'CAAACACGCACCTCAAAGC-3'. qPCR was performed using the QuantiFast SYBR Green PCR kit (Qiagen, Inc., Valencia, CA, USA). Amplification consisted of $20 \mathrm{sec}$ at $95^{\circ} \mathrm{C}$, and $3 \mathrm{sec}$ at $95^{\circ} \mathrm{C}$ followed by $30 \mathrm{sec}$ at $60^{\circ} \mathrm{C}$ for 40 cycles. The reaction was normalized by amplifying samples for glyceraldehyde-3-phosphate dehydrogenase, which served as housekeeping gene (9).

PCR data were analyzed with the 7500 Fast System SDS software version 2.0.5 (Applied Biosystems; Thermo Fisher Scientific, Inc.).

Western blot analysis. Total proteins were extracted from the cells, quantified, separated by sodium dodecyl sulfate-polyacrylamide gel electrophoresis and transferred onto membranes, which were probed with the corresponding primary antibody [monoclonal mouse anti-HPV-E7 (dilution, 1:200; catalog no., MA5-15439; Invitrogen; Thermo Fisher Scientific, Inc.); monoclonal mouse anti-HPV-E6 (dilution, 1:200; catalog no., sc-460; Santa Cruz Biotechnology, Inc.); monoclonal mouse anti-p53 (clone DO-1; dilution, 1:100; catalog no., sc-126; Santa Cruz Biotechnology, Inc.); monoclonal mouse anti-p16 $6^{\text {ink4a }}$ (dilution, 1:100; catalog no., sc-9968; Santa Cruz Biotechnology, Inc.); monoclonal mouse 
A

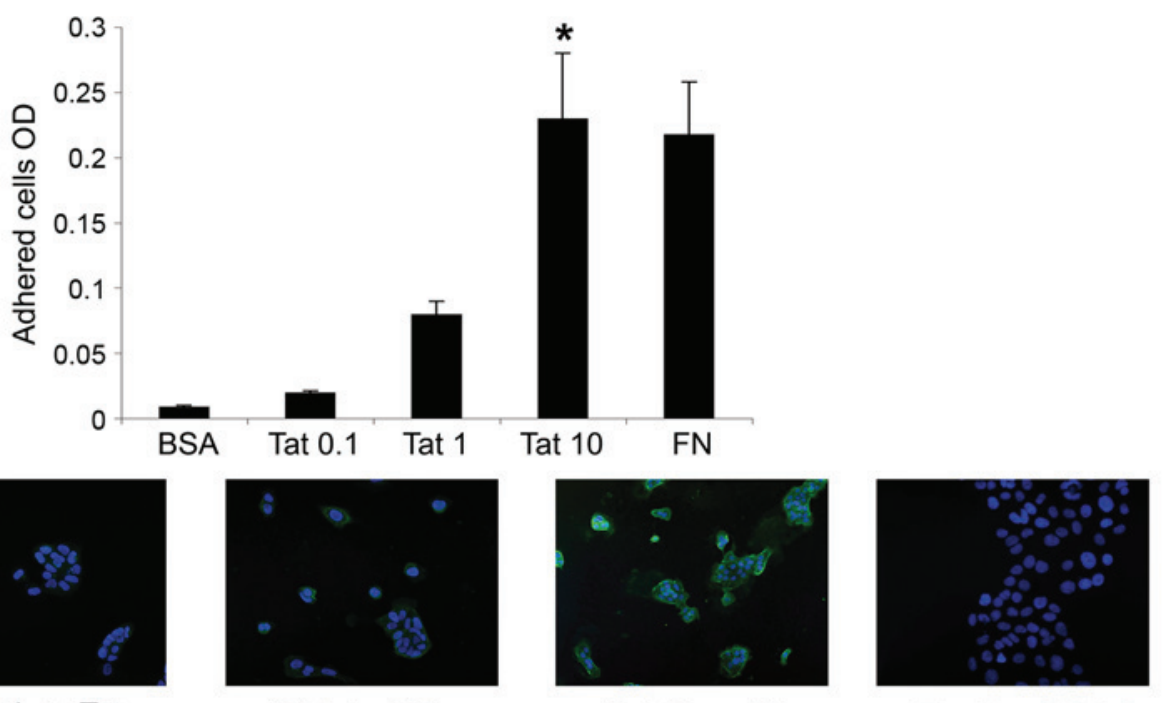

Buffer $+\alpha$ Tat

Tat $0.1+\alpha$ Tat

Tat $1+\alpha$ Tat

Tat $10+\alpha$ Tat

Tat $10+$ CR laG

C

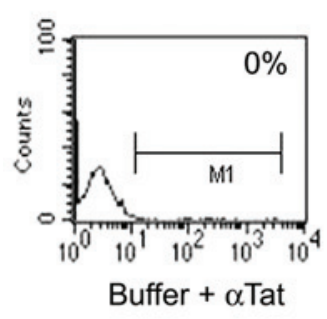

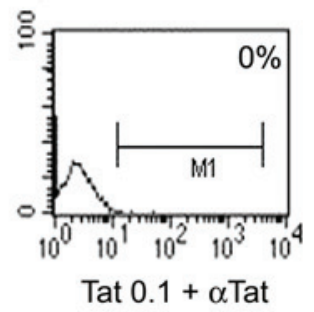

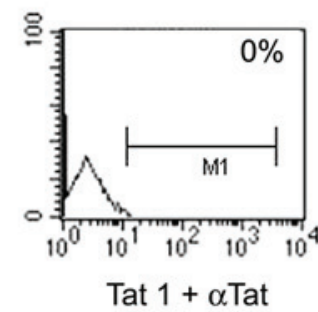

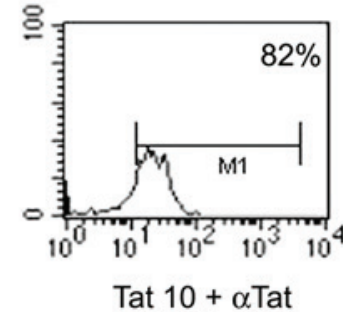

Tat $10+\alpha$ Tat

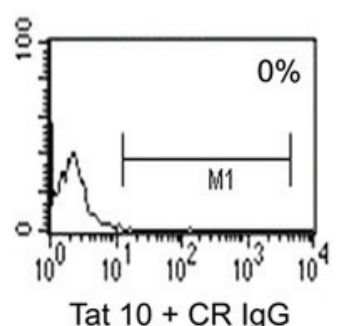

Figure 1. SiHa cells take up micromolar amounts of HIV-1 Tat protein. (A) SiHa cells were seeded on plates coated with $0.1,1$ or $10 \mu \mathrm{g} / \mathrm{ml}$ Tat. BSA or FN concentrations equimolar to $10 \mu \mathrm{g} / \mathrm{ml}$ Tat were employed as the negative or positive control, respectively. Adherent cells were quantified as described in the Materials and methods section. Results are expressed as mean optical density values from three experiments ( $\mathrm{P}<0.05$ ). (B and $\mathrm{C}) \mathrm{SiHa}$ cells were incubated for $30 \mathrm{~min}$ in medium containing $0.1,1$ or $10 \mu \mathrm{g} / \mathrm{ml}$ biologically active Tat or its suspension buffer (phosphate-buffered saline containing $0.1 \%$ BSA, which served as the negative control), and stained with anti-Tat or control antibodies. (B) Tat intracellular localization was visualized by fluorescence microscopy and photographed. Blue color corresponds to SiHa cell nuclei stained with 4',6-diamidino-2-phenylindole, while green color indicated intracellular Tat protein, which was revealed as described in the Materials and methods section. Magnification, x20. (C) The intracellular Tat content was evaluated by intracellular staining and flow cytometry. The percentage of positive cells (compared with isotype-stained samples) is reported in the boxes. The data in panels B and C correspond to a representative experiment. Repeated experiments produced similar results. OD, optical density; BSA, bovine serum albumin; FN, fibronectin; $\alpha$ Tat, anti-Tat antibody; CR, control; IgG, immunoglublin G; M1, marker 1.

anti- $\beta$ actin (dilution, 1:500; catalog no., A5316; SigmaAldrich)] and a specific horseradish peroxidase-conjugated goat anti-mouse secondary antibody (dilution, 1:2,000; catalog no., sc-2031; Santa Cruz Biotechnology, Inc.), as described earlier (9). Filters were developed with the use of the LiteAblot ${ }^{\circledR}$ Plus Enhanced Chemiluminescent Substrate Sample (EuroClone S.p.A., Pero, Italy), and the intensity of the bands was quantified by employing the ChemiDoc XRS+ imaging system (Bio-Rad Laboratories, Inc., Hercules, CA, USA).

Statistical analysis. Data are presented as the mean + standard deviation from 3-4 experiments. Statistical analysis was performed using the SPSS 15.0 software (SPSS Inc., Chicago, IL, USA). P-values were determined with the Student's $t$-test. $\mathrm{P}<0.05$ was considered to indicate a statistical significant difference.

\section{Results}

Initial experiments evaluated whether the HIV-1 Tat protein could promote the adhesion of human cervical cancer cells, thus implying a contact between the surface of these tumor cell types and extracellular Tat. Specifically, SiHa cells were seeded onto plates coated with recombinant Tat protein, immobilised at $0.1,1$ or $10 \mu \mathrm{g} / \mathrm{ml}$. The pro-adhesive extracellular matrix molecule FN was employed as the positive control (12), whereas BSA was used as the negative control. The results indicated that, when immobilised at $10 \mu \mathrm{g} / \mathrm{ml}$, Tat promoted $\mathrm{SiHa}$ cell adhesion to the same extent as FN, while 0.1 or $1 \mu \mathrm{g} / \mathrm{ml}$ of Tat had no significant effect (Fig. 1A).

Considering that cells can internalize the extracellular-bound molecules onto which they are adhered (13), additional experiments evaluated whether SiHa cells could take up extracellular HIV-1 Tat protein. To this end, SiHa cells were exposed to $0.1,1$ or $10 \mu \mathrm{g} / \mathrm{ml}$ of recombinant, biologically active Tat protein, or to its suspension buffer (PBS-0.1\% BSA), which was employed as the negative control. The uptake of Tat was then visualized at 30,60 or $120 \mathrm{~min}$ by fluorescence microscopy. In agreement with the results from the cell adhesion assays, $\mathrm{SiHa}$ cells took up Tat protein only when it was diluted at $10 \mu \mathrm{g} / \mathrm{ml}$, this being fully appreciable at $30 \mathrm{~min}$ (Fig. 1B and data not shown). These findings were confirmed by intracellular staining with anti-Tat or control antibodies and by flow cytometry (Fig. 1C). 
A
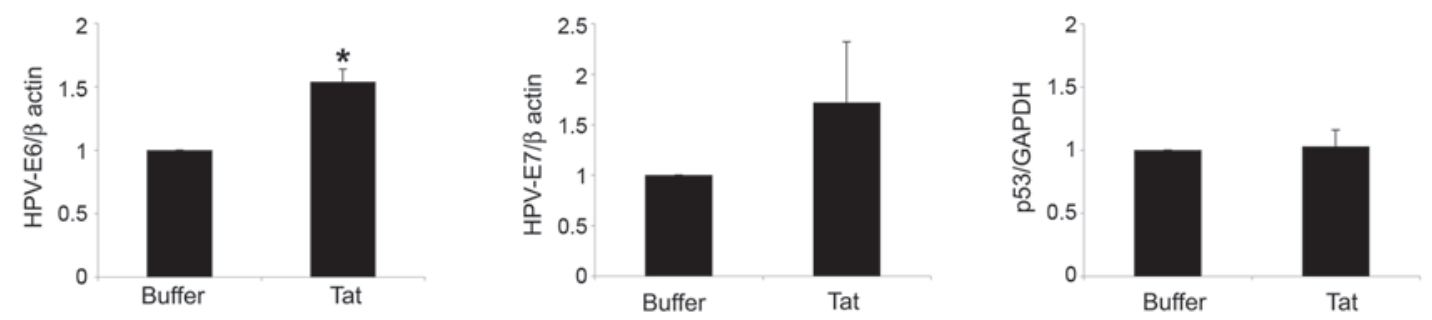

B
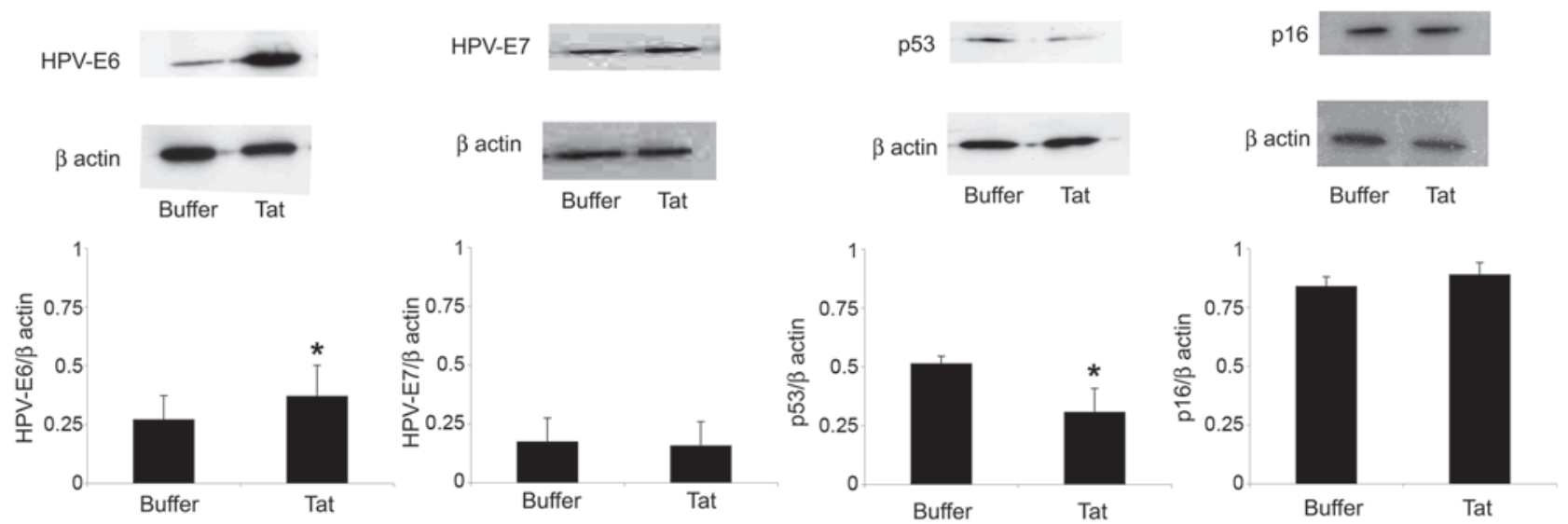

Figure 2. Uptake of extracellular Tat by SiHa cells is followed by a variation on HPV-E6 or p53 levels. SiHa cells were exposed for $48 \mathrm{~h}$ to $10 \mu \mathrm{g} / \mathrm{ml}$ Tat or its buffer. (A) Reverse transcription-quantitative polymerase chain reaction analysis of HPV-E6 (left panel), HPV-E7 (central panel) or p53 (right panel) RNA levels in SiHa cells cultured in the absence or presence of Tat. The results refer to the relative HPV-E6, HPV-E7 or p53 expression, normalized to the levels of $\beta$-actin or glyceraldehyde 3-phosphate dehydrogenase, which served as housekeeping genes. Bars represent the mean \pm SD from four experiments ("P $<0.05$ ). (B) Cells were lysed, and equal amounts of total proteins were electrophoresed and analyzed by western blotting using a monoclonal antibody directed against the E6 or E7 protein of HPV16, human p53 or human p16 ${ }^{\text {ink4a }}$. Blots were re-probed with anti- $\beta$-actin monoclonal antibody to verify equal loading of protein in each lane. The upper panels are representative western blots of HPV-E6, HPV-E7, p53, p16 ${ }^{\text {ink4a }}$ or $\beta$-actin. The lower panels represent the quantitative (densitometric) analysis of HPV-E6, HPV-E7, p53 or p16 ${ }^{\text {ink4a }}$ protein levels (normalized to those of $\beta$-actin) in control or Tat-treated SiHa cells. Bars represent the mean \pm SD from 3-4 experiments ("P<0.05). SD, standard deviation; HPV, human papilloma virus; GAPDH, glyceraldehyde 3-phosphate dehydrogenase; INK4, inhibitor of cyclin-dependent kinase 4.
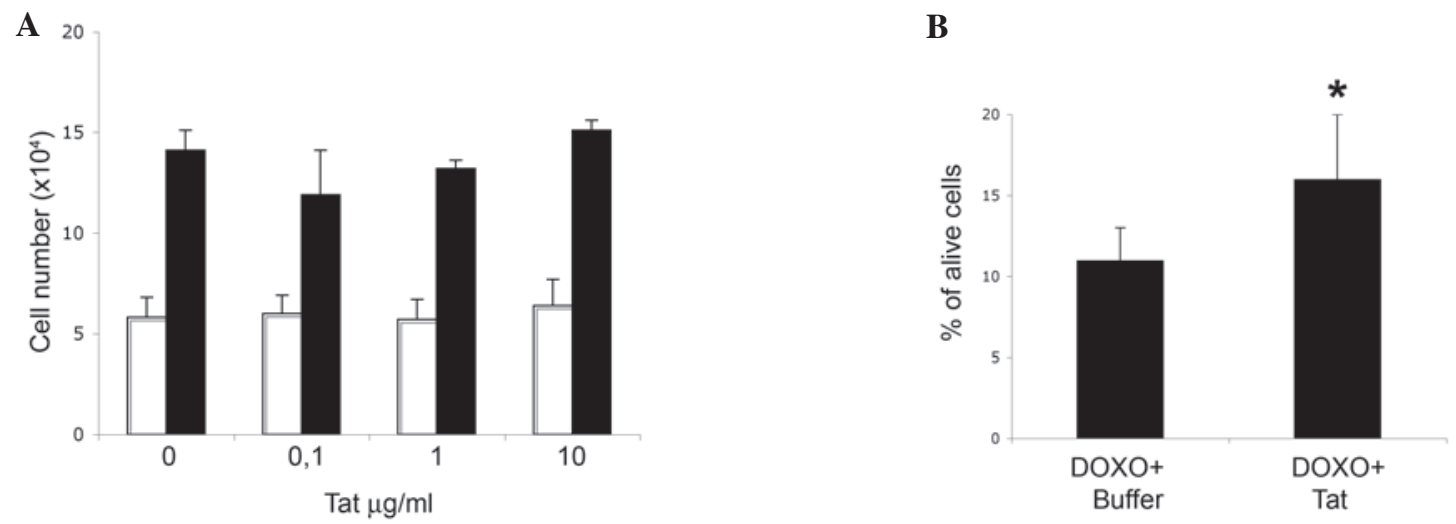

Figure 3. Entry of human immunodeficiency virus-1 Tat protein into SiHa cells partially rescues DOXO cytotoxic effect, with no impact on cell growth. SiHa cells were seeded at a density of $1.5 \times 10^{4}$ cells/well in a 12-well cell culture plate. (A) Number of cells collected after 48 (white bars) or $96 \mathrm{~h}$ (black bars) of culture in medium containing $0.1,1$ or $10 \mu \mathrm{g} / \mathrm{ml}$ Tat, or its buffer (indicated as $0 \mu \mathrm{g} / \mathrm{ml}$ Tat). Data are the mean from two experiments, each performed in duplicate wells. (B) Cells were treated for $48 \mathrm{~h}$ with $10 \mu \mathrm{g} / \mathrm{ml}$ Tat or its buffer, and then grown for additional $48 \mathrm{~h}$ in the absence or presence of $2 \mu \mathrm{M}$ DOXO. The results are expressed as the percentage of alive cells over the total cell number. Data represent the mean \pm standard deviation from three experiments $(\mathrm{P}<0.05)$. DOXO, doxorubicin.

Further assays evaluated whether, following its internalization, the Tat protein could modulate HPV-E6 expression by SiHa cells. As shown in Fig. 2A, SiHa cell exposure to $10 \mu \mathrm{g} / \mathrm{ml}$ Tat increased HPV-E6 RNA levels by 1.54 -fold ( $\mathrm{P}=0.02)$, compared with control cells. In addition, Tat augmented by 1.35-fold ( $\mathrm{P}=0.04)$ the content of HPV-E6 protein in SiHa cells (Fig. 2B).
In this context, Tat (compared with its suspension buffer) upregulated HPV-E7 gene but not protein expression in $\mathrm{SiHa}$ cells; however, these results were not significant (Fig. 2).

The E6 protein of HR-HPV promotes the degradation of the oncosuppressor protein p53 by engaging the cellular proteasome, a cytosolic complex of enzymes that regulates the turnover of intracellular proteins (3). In agreement with its 
capability of upregulating E6 expression, Tat reduced by $40 \%$ $(\mathrm{P}=0.04)$ the protein content of p53 in SiHa cells, while it had no effect on p53 gene expression (Fig. 2).

In contrast to the p53 protein, Tat did not modify the protein levels of the cell cycle inhibitor p16 ${ }^{\text {ink4a }}$ in SiHa cells (Fig. 2B). Consistent with this result, Tat did not increase $\mathrm{SiHa}$ cell growth rate, neither at 48 or $96 \mathrm{~h}$ after its addition to the growth medium (Fig. 3A).

Additional experiments next evaluated whether, in view of its effect on $\mathrm{p} 53$ protein, Tat could reduce SiHa cell sensitivity to doxorubicin, a drug that promotes the death of HR-HPV ${ }^{+}$ cervical cancer cells in a p53-dependent manner (10).

Preliminary cell viability assays indicated that doxorubicin was cytostatic at $0.5-1.5 \mu \mathrm{M}$, and cytotoxic at $2-5 \mu \mathrm{M}$ (data not shown). Based on these data, $\mathrm{SiHa}$ cells were first incubated with Tat protein (using its suspension buffer as control), and then cultured in the presence or absence of $2 \mu \mathrm{M}$ doxorubicin. The results indicated that Tat partially rescued doxorubicin-promoted SiHa cell death (Fig. 3B, P=0.03).

\section{Discussion}

The present study has demonstrated that extracellular, biologically active HIV-1 Tat protein can enter human uterine cervical carcinoma cells, and this is followed by an increase in HPV-E6 protein and RNA levels in the cells. These findings, which are consistent with previous results obtained with HIV-1 Tat DNA (2), suggest a possible link between extracellular Tat protein and the high incidence and clinical aggressiveness of uterine cervical carcinoma observed in HIV/HPV doubly infected women (1).

The present results reveal that the upregulation of HPV-E6 expression promoted by Tat parallels a decrease in the levels of p53 protein, a potent antagonist of uterine cervical carcinoma development and progression $(3,14)$. The lack of any effect on p53 gene expression suggests that Tat reduces p53 protein levels in SiHa cells only indirectly, via an increase of E6 which, in turn, will commit p53 to proteasome-mediated degradation (3).

In addition, it was also observed that, differently from what occurred for $\mathrm{p} 53$, Tat had no effect on the cell cycle inhibitor p16 ${ }^{\text {ink4a }}$. Altogether, these results are consistent with earlier studies reporting that, in cervical carcinoma tissues, low p53 and high p16 ${ }^{\text {ink4a }}$ protein levels are indicative of HR-HPV intensity of expression and predictive of tumor clinical progression (15).

Although the in vitro findings described in the present study were observed at Tat concentrations exceeding those present in the sera of HIV-infected individuals (5), evidence suggests that in vivo uterine cervical cells are likely to be exposed to Tat concentrations higher than its plasma levels. In particular, earlier studies demonstrated that, in tumor lesions of the uterine cervix, epithelial cells express intercellular adhesion molecule (ICAM)-1, a leukocyte-binding cell membrane receptor (16-18). Thus, due to the presence of ICAM-1 on their surface, uterine cervical carcinoma cells would closely contact HIV-infected, Tat-releasing leukocytes.

Notably, inflammation of the uterine cervix is frequent in HIV-infected women $(14,19,20)$. In this context, the capability that inflammatory mediators have to induce ICAM-1 appearance on epithelial cell surface $(21,22)$ could favour the adhesion of HIV-infected leukocytes to the epithelium of the uterine cervix, thus facilitating Tat uptake by cervical epithelial cells prior to their transformation into carcinoma cells.

The present study has demonstrated that extracellular HIV-1 Tat protein is able to enter human uterine cervical carcinoma cells, and that this is followed by upregulation of tumorigenic HPV-E6 and downregulation of anti-tumorigenic p53. Future work will evaluate whether the same events occur when cervical carcinoma cells are co-cultured with HIV-acutely infected, Tatreleasing lymphocytes. In addition, a clinical-epidemiological survey will assess whether the presence of anti-Tat antibodies is associated with a reduced incidence and/or delayed progression of uterine cervical carcinoma in HIV/HPV doubly infected women.

\section{Acknowledgements}

The present study was supported by grants from the Italian Ministry of Health (Rome, Italy) to B.E. and G.B. (grant no., OR/70DF), and from the Italian Ministry of University and Research (Rome, Italy) to G.B. (grant no., RSA/0906). The authors would like to thank P. Arciero (National Institute of Health, Rome, Italy) for technical help.

\section{References}

1. Kang M and Cu-Uvin S: Association of HIV viral load and CD4 cell count with human papillomavirus detection and clearance in HIV-infected women initiating highly active antiretroviral therapy. HIV Med 13: 372-378, 2012.

2. Kim RH, Yochim JM, Kang MK, Shin KH, Christensen R and Park NH: HIV-1 Tat enhances replicative potential of human oral keratinocytes harboring HPV-16 genome. Int J Oncol 33: 777-782, 2008.

3. Vande Pol SB and Klingelhutz AJ: Papillomavirus E6 oncoproteins. Virology 445: 115-137, 2013.

4. Shen R, Richter HE and Smith PD: Early HIV-1 target cells in human vaginal and ectocervical mucosa. Am J Reprod Immunol 65: 261-267, 2011.

5. Barillari G and Ensoli B: Angiogenic effects of extracellular HIV-1 Tat protein and its role in the pathogenesis of AIDS-associated Kaposi's sarcoma. Clin Microbiol Rev 15: 310-326, 2002

6. Henning TR, Kissinger P, Lacour N, Meyaski-Schluter M, Clark R and Amedee AM: Elevated cervical white blood cell infiltrate is associated with genital HIV detection in a longitudinal cohort of antiretroviral therapy-adherent women. J Infect Dis 202: 1543-1552, 2010

7. Calil LN, Edelweiss MI, Meurer L, Igansi CN and Bozzetti MC: p16 INK4a and Ki67 expression in normal, dysplastic and neoplastic uterine cervical epithelium and human papillomavirus (HPV) infection. Pathol Res Pract 210: 482-487, 2014.

8. Fanales-Belasio E, Moretti S, Nappi F, Barillari G, Micheletti F, Cafaro A and Ensoli B: Native HIV-1 Tat protein targets monocyte-derived dendritic cells and enhances their maturation, function, and antigen-specific T cell responses. J Immunol 168: 197-206, 2002.

9. Barillari G, Iovane A, Bacigalupo I, Palladino C, Bellino S, Leone P, Monini P and Ensoli B: Ritonavir or saquinavir impairs the invasion of cervical intraepithelial neoplasia cells via a reduction of MMP expression and activity. AIDS 26: 909-919, 2012.

10. Suh DS, Kim SC, An WG, Lee CH, Choi KU, Song JM, Jung JS, Lee KS and Yoon MS: Differential apoptotic response in $\mathrm{HPV}$-infected cancer cells of the uterine cervix after doxorubicin treatment. Oncol Rep 23: 751-756, 2010.

11. Livak KJ and Schmittgen TD: Analysis of relative gene expression data using real-time quantitative PCR and the 2(-Delta Delta C(T)) Method. Methods 25: 402-408, 2001.

12. Bachman H, Nicosia J, Dysart M and Barker TH: Utilizing fibronectin integrin-binding specificity to control cellular responses. Adv Wound Care (New Rochelle) 4: 501-511, 2015. 
13. Engelholm LH, List K, Netzel-Arnett S, Cukierman E, Mitola DJ, Aaronson H, Kjøller L, Larsen JK, Yamada KM, Strickland DK, et al: uPARAP/Endo180 is essential for cellular uptake of collagen and promotes fibroblast collagen adhesion. J Cell Biol 160: 1009-1015, 2003.

14. Mwakigonja AR, Torres LM, Mwakyoma HA and Kaaya EE: Cervical cytological changes in HIV-infected patients attending care and treatment clinic at muhimbili national hospital, Dar es salaam, Tanzania. Infect Agent Cancer 7: 3, 2012.

15. Conesa-Zamora P, Doménech-Peris A, Orantes-Casado FJ, Ortiz-Reina S, Sahuquillo-Frías L, Acosta-Ortega J, García-Solano J and Pérez-Guillermo M: Effect of human papillomavirus on cell cycle-related proteins p16, Ki-67, Cyclin D1, p53 and ProEx C in precursor lesions of cervical carcinoma: A tissue microarray study. Am J Clin Pathol 132: 378-390, 2009.

16. Coleman N, Greenfield IM, Hare J, Kruger-Gray H, Chain BM and Stanley MA: Characterization and functional analysis of the expression of intercellular adhesion molecule-1 in human papillomavirus-related disease of cervical keratinocytes. Am J Pathol 143: 355-367, 1993.

17. Guo J, Si L and Wang Y: An in situ study on immunostimulatory molecules in cancer cells within the cervical carcinoma tissues. Zhonghua Yi Xue Za Zhi 80: 342-345, 2000 (In Chinese).

18. Chancey CJ, Khanna KV, Seegers JF, Zhang GW, Hildreth J, Langan A and Markham RB: Lactobacilli-expressed single-chain variable fragment $(\mathrm{scFv})$ specific for intercellular adhesion molecule 1 (ICAM-1) blocks cell-associated HIV-1 transmission across a cervical epithelial monolayer. J Immunol 176: 5627-5636, 2006 .
19. Nkwanyana NN, Gumbi PP, Roberts L, Denny L, Hanekom W, Soares A, Allan B, Williamson AL, Coetzee D, Olivier AJ, et al: Impact of human immunodeficiency virus 1 infection and inflammation on the composition and yield of cervical mononuclear cells in the female genital tract. Immunology 128 (Suppl 1): e746-e757, 2009.

20. Mitchell C, Balkus JE, McKernan-Mullin J, Cohn SE, Luque AE, Mwachari C, Cohen CR, Coombs R, Frenkel LM and Hitti J: Associations between genital tract infections, genital tract inflammation, and cervical cytobrush HIV-1 DNA in US versus Kenyan women. J Acquir Immune Defic Syndr 62: 143-148, 2013.

21. Xie M, Hu A, Luo Y, Sun W, Hu X and Tang S: Interleukin-4 and melatonin ameliorate high glucose and interleukin-1 $\beta$ stimulated inflammatory reaction in human retinal endothelial cells and retinal pigment epithelial cells. Mol Vis 20: 921-928, 2014.

22. Thichanpiang $\mathrm{P}$ and Wongprasert K: Green tea polyphenol epigallocatechin-3-gallate attenuates TNF- $\alpha$-induced intercellular adhesion molecule-1 expression and monocyte adhesion to retinal pigment epithelial cells. Am J Chin Med 43: 103-119, 2015. 